\title{
Another way of thinking about ADHD: the predictive role of early attachment deprivation in adolescents' level of symptoms
}

\author{
I. Roskam $\cdot$ M. Stievenart $\cdot$ R. Tessier $\cdot$ \\ A. Muntean - M. J. Escobar • M. P. Santelices • \\ F. Juffer $\cdot$ M. H. Van Ijzendoorn $\cdot$ B. Pierrehumbert
}

Received: 12 October 2012/ Accepted: 27 March 2013/Published online: 20 April 2013

(C) Springer-Verlag Berlin Heidelberg 2013

\begin{abstract}
Purpose Attention deficit and hyperactivity disorder (ADHD) is one of the most frequent disorders in childhood and adolescence. Both neurocognitive and environmental factors have been related to ADHD. The current study contributes to the documentation of the predictive relation between early attachment deprivation and ADHD.

Method Data were collected from 641 adopted adolescents $(53.2 \%$ girls) aged 11-16 years in five countries, using the DSM oriented scale for ADHD of the Child Behavior Checklist (CBCL) (Achenbach and Rescorla, Manual for the ASEBA school-age forms and profiles. University of Vermont, Research Center for Children, Youth and Families, Burlington, 2001). The influence of attachment deprivation on ADHD symptoms was initially tested taking into consideration several key variables that
\end{abstract}

I. Roskam $(\bowtie) \cdot$ M. Stievenart

Psychological Sciences Research Institute, Université catholique de Louvain, Louvain, Belgium

e-mail: isabella.roskam@uclouvain.be

R. Tessier

School of Psychology, Laval University, Quebec, Canada

A. Muntean

Social Work Department, West University of Timisoara,

Timisoara, Romania

M. J. Escobar · M. P. Santelices

Pontificia Universidad Católica de Chile, Santiago de Chile, Chile

F. Juffer - M. H. Van Ijzendoorn

Centre for Child and Family Studies, Leiden University,

Leiden, The Netherlands

B. Pierrehumbert

SUPEA: Lausanne University, Lausanne, Switzerland have been reported as influencing ADHD at the adoptee level (age, gender, length of time in the adoptive family, parents' educational level and marital status), and at the level of the country of origin and country of adoption (poverty, quality of health services and values). The analyses were computed using the multilevel modeling technique.

Results The results showed that an increase in the level of ADHD symptoms was predicted by the duration of exposure to early attachment deprivation, estimated from the age of adoption, after controlling for the influence of adoptee and country variables. The effect of the age of adoption was also demonstrated to be specific to the level of ADHD symptoms in comparison to both the externalizing and internalizing behavior scales of the CBCL.

Conclusion Deprivation of stable and sensitive care in infancy may have long-lasting consequences for children's development.

Keywords ADHD - Regulation - CBCL - Deprivation · Adoption $\cdot$ Adolescence $\cdot$ Culture

\section{Introduction}

Attention deficit and hyperactivity disorder (ADHD) is characterized by inattention, hyperactivity and impulsivity. It is one of the most frequent disorders in childhood and adolescence. The worldwide pooled prevalence of ADHD is $5.29 \%$, with gender-related differences, i.e. a higher prevalence in boys than in girls [46, 66]. Age-related differences have also been reported in developmental studies that have found a change in trajectories, with for example a clear reduction in ADHD symptomatology for inattention, hyperactivity and impulsivity at the moment of the 
transition to middle school for young adolescents [33]. In several studies, ADHD has been found to interfere with adolescents' personal, social and academic development $[19,38]$.

The aim of the current research is to examine the predictive role of early experience of attachment deprivation for ADHD symptoms in adolescence. Two bodies of research have been dedicated to this topic. First, there have been studies in which participants' attachment and ADHD have been assessed and related to each other. Second, there have been studies of subjects, who have reported deprivation in attachment, in particular adoptees. In this second set of studies, no assessment of the children's attachment pattern has been completed prior to their adoption for practical reasons. It is assumed that adoptees are at risk of insecure attachment relationships because of their background of institutional, unresponsive caregiving and neglect $[49,65,67]$.

The etiology of ADHD

Both neurocognitive and environmental factors have been related to ADHD.

According to the cognitive theories, ADHD could be explained by a low level of executive functioning characteristics, such as inhibiting prepotent responses, interference control and cognitive flexibility [4]. It could also be due to a motivation deficit $[58,59]$ or to a deficit in temporal processing [61]. Neurobiological explanations, such as the crucial role of the dopamine transporter gene have also been proposed [8]. It has nevertheless been recognized that neurocognitive factors cannot explain the whole variance in ADHD symptoms [45].

Environmental factors have been reported as implicated in the etiology of ADHD [23]. Researchers have examined whether and to what extent ADHD symptoms are related to the characteristics of the cultural and the family environments. With regard to the characteristics of the cultural environment, ADHD has been considered as a relevant construct across cultures [6, 9]. However, cross-cultural variations have been found in the assessment of ADHD symptoms in children and adolescents as well as in parental explanatory models of ADHD [10, 34, 48]. In addition, findings among adoptees have recently been published showing the importance of the country of origin, in particular in Eastern Europe, for attention problems later on [3].

With regard to the characteristics of the family environment, ADHD has been found to be more common among children reared in families experiencing adversity such as marital discord, low socio-economic status, large family size, paternal criminality, and maternal mental disorder [44, $51,52,70]$. ADHD has also been found to be related to negative parent-child relationships. Numerous studies have reported that coercive parenting styles are predictive of ADHD symptoms $[18,29]$. However, much less attention has been paid to the attachment framework in order to document the importance of the quality of parent-child relationship in ADHD. The attachment framework provides an interesting new way of thinking about ADHD. In particular, the recent developments in attachment theory have shown the role played by attachment security in the child's emotional and behavioral self-regulation [69, 72], and this important role has also been stressed in connection with ADHD [5, 11, [71]. The attachment framework is actually a theory about how a child learns to regulate his/her own affect as a result of how sensitively caregivers respond to the child's needs and help $\mathrm{him} / \mathrm{her}$ to learn to self-regulate [39]. Attachment theory is a model of the development of self-regulation, and where selfregulation is disturbed, as is the case in ADHD, this suggests that attachment theory will be relevant to consideration of the etiology of the syndrome.

Attachment and ADHD

Attachment theory assumes that the early caregiver-child relation is crucial for the emergence of the self-regulatory skills [39] the lack of which is implicated in ADHD symptoms $[5,71]$. The predictive link between attachment and ADHD has been empirically observed. It has been illustrated in several clinical reports and case studies reporting insecure attachment among ADHD children and adolescents [14, 15, 42, 62]. The link between attachment and ADHD has also been cross-sectionally examined. These studies documented the co-occurrence of ADHD symptoms and insecure attachment. For example, insecure attachment score has been related to hyperactivity and inattention symptoms among 384 11-16 year-old adolescents [30]. Control-case studies have also provided support for the relation between attachment insecurity and ADHD. For example, 19 boys aged 5-10 years with a diagnosis of ADHD were compared with 19 control children with respect to attachment. Consistent support was found for the association between attachment insecurity and ADHD [13]. Finally, the predictive relation between attachment and ADHD has been supported by only a few longitudinal studies. For example, ADHD has been assessed among 53 6-8 year-old children identified as having significant levels of disorganized attachment at 1 year of age. The results showed that attachment disorganization was correlated to ADHD scores for both inattention and hyperactivity symptoms 6 years later [45].

\section{ADHD in adoptees}

Adoptees have experienced parental separation and early attachment deprivation, i.e. lack of assistance with affect regulation in early childhood, lack of reciprocity, or lack of 
empathetic emotional mirroring by the caregiver and associated emotional containment, which potentially harm infant functioning and later development. Neglect in 1 months of life, i.e. the lack of caregiver's care and nurturance, has been found to have deleterious effects on children's cognitive, socio-emotional, and behavioral development [24, 40, 55, 68]. A meta-analysis of 98 adoptee-control studies concluded that despite low to moderate effect sizes, adoptees displayed on average higher levels of both externalizing and internalizing problems than controls [28]. In addition, when compared with their non-adopted siblings, adoptees' adjustment was worse in late adolescence [73].

More specifically, ADHD has been considered as a characteristic outcome of early deprivation. Indeed, inattention and overactivity symptoms have even been thought to form an institutional deprivation syndrome [31, 50, 60]. Both control-case and follow-up studies from the adoption literature provide interesting information about the influence of early attachment deprivation on ADHD.

Recent case-control studies have consistently reported group differences, with more pronounced ADHD symptoms in adoptees than in controls. These group differences were seen to be moderated by the age of adoption, which can be regarded as an indicator of the duration of exposure to early attachment deprivation [31, 37]. For example, group differences have been found between adopted children aged 8-11 years and controls with respect to ADHD symptoms [74]. A nuanced picture emerged from this study, which compared children with pronounced early deprivation and neglect, i.e. those adopted after 12 months of age and having previously been mostly in institutional care, with children with moderate early deprivation, i.e. those adopted before 8 months of age and having previously been mostly in foster care. These results suggest that the duration of exposure to early deprivation moderated the differences between the groups. Group differences were also reported in another recent study, in which the rates of ADHD medication were found to be higher among 10-15 year-old adoptees than among controls. It was also reported that the rate of such medication was likely to increase with higher age at adoption [35].

Follow-up studies have delivered results consistent with those of control-case studies. They also help document the role of individual, family and cultural risk factors in adoptees' behavioral adaptation. Lower levels of behavioral adjustment have been found to be predicted by age of adoption [53] and other risk factors, such as current age, single parenthood and culture of origin [1, 17, 75]. More specifically, ADHD seems to increase with the age of adoption, suggesting that exposure to early attachment deprivation provokes self-regulatory deficits, thus increasing children's vulnerability to ADHD symptoms [20, 37, 54].
The current study

The current study contributes to the documentation of the predictive relation between early attachment deprivation and ADHD. Data have been collected in five countries among 641 adolescents aged 11-16 who were adopted before the age of 7 years. The influence of attachment deprivation on ADHD symptoms was initially tested by taking into consideration several key variables at the adoptee and country levels that have been reported as influencing behavioral issues, in particular ADHD. It will be recalled that age- and gender-related differences in ADHD have been found [33, 46] and the risk for ADHD has turned out to be higher in families experiencing adversity such as low socio-economical status or marital discord [44, 52, 70]. Cross-cultural variations in the assessment of ADHD symptoms as well as in the explanatory models of the syndrome have been reported [10, 34, 48], and variations in the level of attention problems have been displayed among adoptees according to their country of origin [3]. It was hypothesized that an increased level of ADHD symptoms was predicted by the duration of exposure to early attachment deprivation, estimated from the age of adoption, over and above the influence of adoptee variables, i.e. age, gender, length of time in adopting family, parents' educational level as a proxy of SES and marital status, and country variables, i.e. social and economic development, quality of health services and values. It was also hypothesized that ADHD symptoms are a characteristic outcome of early deprivation [31, 60]. A nonsignificant main relation was therefore expected between the duration of exposure to early deprivation, estimated from the age of adoption, and other outcomes, in particular externalizing and internalizing behavior.

\section{Method}

Sample

This study is part of the Attachment in Adopted Adolescents Research Network (AAARN). For the current research, the inclusion criteria were that the child had been adopted before the age of 7 years, i.e. a maximum of 84 months of early attachment deprivation, that they were aged 11-16 years, and that they knew they had been adopted.

\section{Adoptee variables}

Data were collected from $641,11-16$ year-old $(M=13.45$, $\mathrm{SD}=1.64)$ adolescents (53.2\% girls). The majority had been adopted from another country $(93 \%)$. Prior to their 
adoption, most children had lived in institutions that provided them with adequate physical resources but not consistent, responsive caregiving. Therefore, the age of adoption, i.e. the number of months spent in the country of origin, ranging from 0 to 82 months $(M=16.50$, $\mathrm{SD}=20.08$ ), was considered as a measure of the duration of exposure to early attachment deprivation. On the other hand, the length of time in the adoptive family was also considered to avoid confusing causal effects, as the symptoms may have been aggravated by the behavior of the adoptive parents. The length of time in the adoptive family ranged from 4 to 17 years $(M=11.89, \mathrm{SD}=2.27)$.

The educational level of the adoptive parents was taken as a proxy for socio-economic status (SES). Educational level is highly correlated to SES in most developed countries [43]. Moreover, owing to the current worldwide economic context, educational level is preferred as a stable indicator, rather than for example, family income, which may fluctuate. The adoptive parents' educational level was classified into five groups: elementary school $(N=46$ (7.2\%) mothers and $N=48$ (7.5\%) fathers), secondary school $(N=159(24 \%)$ mothers and $N=130(20.3 \%)$ fathers), undergraduate studies $(N=199(31 \%)$ mothers and $N=163(25.4 \%)$ fathers), graduate studies $(N=173$ (27\%) mothers and $N=181(28.2 \%)$ fathers) and postgraduate studies $(N=62(9.7 \%)$ mothers and $N=93$ $(14.5 \%)$ fathers). Note that this information was missing for 2 mothers and 26 fathers, mostly in the case of singleparent families. The data for the single mother or single father were considered for these families. To reduce the number of constructs in the analyses, the parents' educational level was averaged from the mother's and the father's levels $(r=0.56, p<0.001)$.

Marital status was considered in a dichotomous manner to contrast two-parent families with adoptive parents living together $(N=533,83.1 \%)$ and alternative situations of single parenthood with the parent living alone (single parent, divorced or widowed) or living with a partner other than the other adoptive parent $(N=96,15 \%)$. Note that this information was missing for $12(1.9 \%)$ families.

\section{Country variables}

The adolescents had been adopted in Canada $(N=367$, $57.3 \%)$, The Netherlands $(N=174,27.1 \%)$, Romania $(N=43,6.7 \%)$, Belgium $(N=33,5.1 \%)$ and Chile $(N=24,3.7 \%)$. Several characteristics of both the adoptive country and the country of origin were considered in the current study.

The adopted adolescents came from 30 different countries: 108 from Sri Lanka (16.8\%), 83 from Romania $(12.9 \%), 70$ from China (10.9 \%), 59 from South Korea $(9.2 \%), 58$ from Colombia (9\%), 48 from Mexico
(7.5\%), 47 from Haiti (7.3\%), 37 from Russia (5.8 \%), 25 from Taiwan $(3.9 \%), 25$ from Chile (3.9\%), 12 from Guatemala (1.9\%), 11 from Bolivia (1.7\%), 11 from Vietnam (1.7\%), 9 from Brazil (1.4\%), 6 from El Salvador $(0.9 \%), 5$ from Peru $(0.8 \%), 4$ from Ethiopia (0.6\%), 3 from Costa Rica (0.5\%), 3 from the Philippines $(0.5 \%), 3$ from Poland $(0.5 \%), 3$ from Honduras $(0.5 \%)$, 2 from Thailand $(0.3 \%), 2$ from Belgium $(0.3 \%), 1$ from Ukraine $(0.2 \%), 1$ from Cape Verde $(0.2 \%), 1$ from Bulgaria $(0.2 \%), 1$ from Cambodia $(0.2 \%), 1$ from India $(0.2 \%), 1$ from Lithuania $(0.2 \%)$, and 1 from Venezuela $(0.2 \%)$

Because it was not possible to record data at an individual level concerning the characteristics of children's caregiving settings in their country of origin, we chose to extrapolate from the global characteristics of childcare and health conditions in the countries of origin. It was considered that the level of social and economic development as well as the quality of the health system in the country of origin may have influenced the quality of the caregiving environment in an institution prior to adoption. These cultural characteristics could therefore impact the adolescents' level of ADHD symptoms. They are shared by all participants coming from the same cultural background. In taking them into consideration in the current study, we sought to disentangle the effect of duration of exposure to early attachment deprivation at the individual level from the effect of shared cultural experience of health system and care services. First, the social and economic development in the country of origin was assessed using the Human Development Index (HuDI), which was developed by the United Nations Development Programme and published in 2008. It is provided by the CIA World Factbook [12] with the collaboration of the Organisation for Economic Co-operation and Development (OECD) and the World Health Organization (WHO). In the HuDI, the higher the score, the higher the social and economic development in the country. Indicators are used to measure the critical indicators of life expectancy, educational attainment and income. In our sample, the HuDI scores in the countries of origin ranged from 0.35 (the lowest score, for Ethiopia) to 0.90 (the highest score, for Belgium) ( $M=0.75, \mathrm{SD}=0.08)$. Second, the quality of the health system was assessed by means of the ranking given by the World Health Organization. Five performance indicators were used to measure health systems in 191 WHO member states: overall level of population health; health inequalities (or disparities) within the population; overall level of health system responsiveness (a combination of patient satisfaction and how well the system acts); distribution of responsiveness within the population (how well people of varying economic status find that they are served by the health system); and the distribution of the health system's 
financial burden within the population (who pays the costs). The WHO ranking provides relative scores, i.e. societies are compared with other societies. The higher the rank, the better the health system in the country. In our sample, the WHO ranking in the countries of origin ranged from 21 (the highest rank, for Belgium) to 180 (the lowest rank, for Ethiopia) $(M=92.38, \mathrm{SD}=46.18)$. The correlation between the HuDI score and the WHO ranking was $-0.61, p<0.001$.

With regard to the countries of adoption, it was considered that both cultural values and the quality of the health system could influence the adolescents' level of ADHD symptoms. These cultural characteristics could hence impact expectations about the behavioral adjustment of adolescents according to cultural standards of normality $[16,63]$, as well as the quality of care and mental health services in the country of adoption, and the support and help given to the adoptive family where necessary. First, the quality of health system in the country of adoption was assessed using the WHO ranking as described above. In our sample, the WHO ranking in the countries of adoption ranged from 17 (the highest rank, for the Netherlands) to 99 (the lowest rank, for Romania) $(M=28.21, \mathrm{SD}=12.21)$. Second, the cultural values in the countries of adoption were considered on the basis of the work of Hofstede [26], in particular the individualism-collectivism dimension for each of the five countries under consideration. The high end of the collectivism-individualism dimension can be defined as "a preference for a loosely knit social framework in which individuals are expected to take care of themselves and their immediate families only". Its opposite, collectivism, represents "a preference for a tightly knit framework in society in which individuals can expect their relatives or members of a particular in-group to look after them in exchange for unquestioning loyalty. A society's position on this dimension is reflected in whether people's self-image is defined in terms of ' $\mathrm{I}$ ' or 'we' [25]. The collectivism-individualism dimension provides relative scores, i.e. countries are compared with other countries. The higher the score, the higher the level of individualism in the country. In our sample, the individualism scores in the countries of adoption ranged from 23 (the lowest score, for Chile) to 80 (the highest score, for both Canada and the Netherlands $)(M=76.02, \mathrm{SD}=11.46)$. The correlation between the WHO ranking and the individualistic score was $-0.59, p<0.001$.

\section{Data collection procedure}

All of the adolescents came from a community sample. Canadian data were extracted from a large dataset from the Quebec study on international adoption [21, 64]. The Canadian original dataset was obtained following authorization from the Cour de la Jeunesse of Quebec giving the authors access to the adoption files. For the current study, a selection of subjects corresponding to the three criteria of inclusion (see above) was made. The selected families received questionnaires by mail. A letter signed by the Secretary for the International Adoption was enclosed with the questionnaire, inviting the parents to participate. A letter of consent was also included, with a brief description of the study. The response rate was $36.8 \%$. In The Netherlands, the questionnaires on behavior problems were completed within a longitudinal adoption study in which internationally adopted children were followed from infancy to adolescence [7, 27]. At the start of the study, adoptive families were randomly recruited through Dutch adoption organizations. In adolescence, the adoptive families were visited at home to conduct assessments and interviews, and to administer questionnaires. Ethical guidelines were followed throughout the study and all participants gave informed consent before their inclusion in the study. At the time of the current study, adolescents from 190 families corresponded to the three criteria of inclusion. Only 15 of them (7.9\%) were not willing to participate. The Romanian data were collected with the collaboration of the governmental adoption service. Cooperation agreements were established with 9 of the 47 Romanian counties. In each of the nine counties, the child protection system established prior contact with the families that had been selected on the basis of the three selection criteria as described above. All of the families contacted within the 2-years period set for the current research project agreed and were then contacted by the research team for a meeting that took place at home or at the child protection service. Belgian questionnaires were completed by adoptive families from the French-speaking part of the country, who were willing to participate. These families were informed about the research project by social networks or by word of mouth. All the families that voluntarily contacted the research team with a view to participating within the 6 months period set for this project and that satisfied the inclusion criteria were included. Eight trained master's students visited the parents and adolescents at home in order to describe the study and give instructions on completing the questionnaires. Chilean families that met the three criteria for inclusion were recruited from the registry of adoptions at the three state agencies authorized to conduct adoptions in Chile: "SENAME" (National Youth Service), "Fundación Chilena para la Adopción" and "Fundación San José para la Adopción”. Adoption agencies initially contacted 71 families to invite them to participate in the study. Thirty-seven families $(52.1 \%)$ agreed to being contacted by the research team. Of these, seven families finally decided to withdraw: three families did not want to stir up past issues, three adolescents refused to participate and one adolescent did not yet know he had been adopted. Six additional cases were 
excluded because they did not meet the inclusion criteria: one adolescent had incurred a developmental disorder, in four cases, the adoption was late (after 84 months of age), and one adolescent was more than 16 years old. Finally, the Chilean sample consisted of 24 adoptive families (33.8\%). The completion of the questionnaires was organized at home. The Ethics Committee of the School of Psychology of the Pontifica Universidad Católica de Chile approved the study. All participants gave signed informed consent.

\section{Outcome measure}

The outcome variable was the current level of ADHD symptoms in adoptees assessed with the DSM-oriented scale for attention deficit/hyperactivity problems of the Child Behavior Checklist (CBCL) covering ages 6-18 years [2]. The DSM-oriented scale for attention deficit/hyperactivity problems is composed of seven items focusing on inattention, e.g. cannot concentrate, hyperactivity, e.g. cannot sit still, and impulsivity, e.g. impulsive. Strong evidence for the reliability and convergent and discriminative validity of the scale has been provided [32, 41]. The DSM-oriented scale for ADHD was completed by the adoptive mothers. The internal consistency was good, with $\alpha=0.82$ in the whole sample and $\alpha$ ranging from 0.72 to 0.88 according to the five subsamples (Canada,The Netherlands, Romania, Belgium, Chile). Data were checked for normality. The test for normality was significant (Kolmogorov-Smirnov(KS) $\quad(641)=0.17$, $p<0.001$ ).

Two other subscales of the CBCL, i.e. the externalizing and internalizing behavior scales, were used to test the specificity of the relation between the age of adoption and the level of ADHD symptoms. The externalizing behavior scale encompasses the rule-breaking and aggressive behavior syndrome scales. The internalizing behavior scale encompasses the anxious/depressed, somatic complaints and withdrawn syndrome scales. Since the externalizing and internalizing behavior scales were closely correlated to the DSM-oriented scale for ADHD with $r=0.75$, $p<0.001$ and $r=0.55, p<0.001$, respectively, the residuals of externalizing and internalizing scores have been considered as outcomes in the analyses. Data were checked for normality. The test for normality was significant both for the externalizing behavior subscale (KS $(641)=0.13, p<0.001)$ and the internalizing behavior subscale $(\mathrm{KS}(641)=0.13, p<0.001)$.

\section{Statistical analysis}

A preliminary set of analyses was computed to test the main relation between the age of adoption and the level of ADHD symptoms irrespective of the adolescents' country of origin and adopting country, in a classical hierarchical regression analysis taking account of the adoptee control variables (age, gender, length of time in the adoptive family, parents' educational level and marital status). Moreover, the specificity of this relation was tested by considering the externalizing and internalizing behavior scales of the CBCL in two similar hierarchical regression analyses. Note that because of close correlations between the length of time in the adoptive family and both age and age of adoption, with $r=0.68, p<0.001$ and $r=-0.71$, $p<0.001$, respectively, the residuals of the length of time in the adoptive family were entered as a predictor.

Second, the data were considered using the multilevel modeling technique [47]. The Hierarchical Linear Model (HLM) is a statistical (maximum likelihood) procedure designed to address the unit of analysis problem in multilevel analyses. HLM accounts for the interdependence of adolescents from the same country of origin and adopted in the same country. A two-level HLM was computed in the current study [36, 56]. It models both country-level and adoptee-level variance on the outcome, i.e. the level of ADHD symptoms. Each adoptee was therefore nested in a level 2 group according to both country of origin and country of adoption. Adoptee variables, i.e. those having a different value for each adolescent, were considered as predictors at level 1 , while country variables, i.e. those having a common value for all the adolescents sharing the same country of origin and country of adoption, were entered as predictors at level 2. All available groups were considered at level 2 since "In most research, the group sizes $n_{j}$ are variable between groups. [...] This does not constitute a problem for the application of the hierarchical linear model in any way. The hierarchical linear model can even be applied if some groups have size $n_{j}=1$, as long as some other groups have greater sizes" [57]. The total number of groups was 42 with their size varying from 1 to 108. The conditions were met for computing an HLM equation $[36,56,57]$.

\section{Results}

Preliminary analyses

The results of the classical hierarchical regression analysis are displayed in Table 1 .

The results show that considering age, gender, length of time in adoptive family, parents' educational level and marital status in a first step, the level of ADHD symptoms was predicted by age, gender and length of time in adoptive family. As expected, the level of ADHD symptoms was seen to decrease with age. In addition, boys displayed a higher level of symptoms than girls. Finally, the longer the 
Table 1 Regression analysis predicting the level of ADHD symptoms, externalizing and internalizing behavior

\begin{tabular}{llll}
\hline & $\begin{array}{l}\text { Level of } \\
\text { ADHD } \\
\text { symptoms }\end{array}$ & $\begin{array}{l}\text { Externalizing } \\
\text { behavior }\end{array}$ & $\begin{array}{l}\text { Internalizing } \\
\text { behavior }\end{array}$ \\
\hline $\begin{array}{llll}\text { Step 1 } \\
\text { Age }\end{array}$ & $-0.105^{* *}$ & $0.120^{* *}$ & 0.053 \\
Gender & $0.217^{* * *}$ & -0.013 & $-0.168^{* * *}$ \\
$\quad$ Length of time in & $-0.164^{* * *}$ & -0.038 & $-0.097^{*}$ \\
$\quad$ adoptive family & & & \\
$\quad$ Educational level & 0.032 & 0.013 & -0.025 \\
Marital status & -0.049 & $-0.111^{* *}$ & -0.060 \\
$R^{2}$ & $7.5 \%$ & $2.2 \%$ & $4.6 \%$ \\
Step 2 & & & -0.021 \\
Age of adoption & $0.208^{* * *}$ & 0.028 & $0 \%$ \\
$\Delta R^{2}$ & $5 \%$ & $0 \%$ & $4.6 \%$ \\
Total $R^{2}$ & $12.5 \%$ & $2.2 \%$ & \\
\hline
\end{tabular}

$* p<0.05, * * p<0.01, * * * p<0.001$

time spent in the adoptive family, the lower the level of ADHD symptoms. The variance components indicated that $7.5 \%$ of the total variance was explained in this first model by the five adoptee control variables. The inclusion of the age of adoption in the second step showed that this variable significantly predicted the level of ADHD symptoms over and above the adoptee control variables. The variance components indicated that $12.5 \%$ of the total variance was explained in this second model (5\% more than in the first model).

The specificity of the relation between the age of adoption and the level of ADHD symptoms was tested in two similar hierarchical regression analyses with the residuals of both externalizing and internalizing behavior as outcomes. In the first step, externalizing behavior was predicted by age and marital status. The level of externalization was seen to increase with the age and adolescents in alternative marital situations displayed higher levels of externalizing behavior than those living with the adoptive parents together. The variance components indicated that $2.2 \%$ of the total variance was explained in this first model by the adoptee control variables. In the second step, the age of adoption was not significantly related to externalizing behavior and no significant additional variance was added to the first model.

In the first step, internalizing behavior was predicted by gender and by length of time in adoptive family. The longer the time spent in the adoptive family, the lower the level of internalization. In addition, girls displayed higher levels of internalizing behavior than boys. The variance components indicated that $4.6 \%$ of the total variance was explained in this first model by the adoptee control variables. In the second step, the age of adoption was not significantly related to internalizing behavior and no significant additional variance was added to the first model.

Multilevel analysis

Before modeling our main research question for the level of ADHD among adolescents, we ran an unconditional model (with no predictors) to see which part of the total variation was attributable to the adoptee and the country levels. The results from the random section indicated both individual and cultural significant variability and showed that it was appropriate to examine the influence of several predictors of the level of ADHD symptoms in conditional models.

A first conditional model with adoptee control variables was analyzed to see which part of the total variation was due to the adoptee control variables, i.e. age, gender, length of time in adoptive family, parents' educational level and marital status. Significant effects of the length of time in adoptive family and gender were found. The longer the time spent in the adoptive family, the lower the level of ADHD symptoms. In addition, boys displayed higher levels of ADHD symptoms than girls. The variance components indicated that $5.31 \%$ of the total variance was explained by the model.

A second conditional model was analyzed to test our main hypothesis, i.e. the specific effect of the age of adoption on the level of ADHD symptoms, controlling for the adoptee variables (age, gender, length of time in adoptive family, parents' educational level and marital status), and taking into consideration the variance at the adoptee and country levels.

Does the age of adoption predict the level of ADHD symptoms in adolescence across different groups of adoptees? The data presented in Table 2 suggest that the answer is yes: a higher age of adoption was significantly related to a higher level of ADHD symptoms. The significant coefficient meant that each additional month in the age of adoption resulted in an increase of 0.020 in the level of ADHD symptoms. The variance components indicated that $8.82 \%(3.51 \%$ more than in the first conditional model) of the total variance was explained by the model.

The third conditional model was analyzed as a full model with adoptee variables at level 1 and country variables at level 2. It investigated the extent to which the age of adoption influenced the adoptees' level of ADHD symptoms, controlling simultaneously for adoptee and country characteristics and taking into account the variance at the adoptee and country levels. The analysis of the third conditional model revealed that, when other adoptee and country characteristics were controlled for, the age of adoption remained significantly related to the level of 
Table 2 Multilevel unconditional model, conditional models with adoptee-level and country-level variables

\begin{tabular}{|c|c|c|c|c|c|c|c|c|}
\hline Parameter & Estimate & SE & Estimate & SE & Estimate & SE & Estimate & SE \\
\hline \multicolumn{9}{|l|}{ Fixed } \\
\hline Intercept & $3.960 * * *$ & $(0.31)$ & $4.909 * *$ & $(1.66)$ & $5.466^{* *}$ & $(1.69)$ & $6.173 * *$ & $(1.89)$ \\
\hline \multicolumn{9}{|l|}{ Adoptee variables } \\
\hline Age & & & -0.098 & $(0.11)$ & -0.164 & $(0.12)$ & -0.164 & $(0.11)$ \\
\hline Gender & & & $0.509 * * *$ & $(0.12)$ & $0.512 * * *$ & $(0.12)$ & $0.501 * * *$ & $(0.12)$ \\
\hline Length of time in adoptive family & & & $-0.314 * *$ & $(0.10)$ & $-0.366^{* *}$ & $(0.11)$ & $-0.313^{* *}$ & $(0.12)$ \\
\hline Educational level & & & 0.140 & $(0.17)$ & 0.121 & $(0.10)$ & 0.146 & $(0.10)$ \\
\hline Marital status & & & -0.134 & $(0.22)$ & -0.158 & $(0.22)$ & -0.139 & $(0.22)$ \\
\hline Age of adoption & & & & & $0.020 * *$ & $(0.00)$ & $0.021 * * *$ & $(0.01)$ \\
\hline \multicolumn{9}{|l|}{ Country variables } \\
\hline HuDI in country of origin & & & & & & & -0.239 & $(0.28)$ \\
\hline WHO ranking in country of origin & & & & & & & $-0.013 *$ & $(0.01)$ \\
\hline Individualistic value in adoptive country & & & & & & & 0.001 & $(0.01)$ \\
\hline WHO ranking in adoptive country & & & & & & & $-0.027^{*}$ & $(0.01)$ \\
\hline \multicolumn{9}{|l|}{ Random } \\
\hline \multicolumn{9}{|l|}{ Variance components } \\
\hline Adoptee-level & $82.66 \%$ & & $81.51 \%$ & & $81.65 \%$ & & $81.54 \%$ & \\
\hline Country-level & $17.33 \%$ & & $13.18 \%$ & & $9.53 \%$ & & $8.53 \%$ & \\
\hline Explained & & & $5.31 \%$ & & $8.82 \%$ & & $9.93 \%$ & \\
\hline Deviance & $3,290.68$ & & $3,280.58$ & & $3,284.65$ & & $3,299.27$ & \\
\hline
\end{tabular}

$* p<0.05 * * p<0.01 * * * p<0.001$

ADHD symptoms. Moreover, the WHO rankings of both the country of origin and the country of adoption were significantly related to the level of ADHD symptoms. The results suggest that, when adoptee and other country characteristics were controlled for, adolescents from the groups at level 2 with a higher ranking in both their country of origin and their country of adoption displayed lower levels of ADHD symptoms. In other words, adolescents displayed lower levels of ADHD symptoms if they came from a country with a better health system and if they had been adopted in a country with a better health system. The significant coefficient meant that an improvement of one position in the WHO ranking resulted in a decrease in the level of ADHD symptoms of 0.013 for the country of origin and 0.027 for the country of adoption. The introduction of the country variables accounted for about $1.11 \%$ of additional explained variance.

The results are displayed in Table 2 for the models.

\section{Discussion}

The main purpose of the current research was to study the predictive role of early attachment deprivation on the level of ADHD symptoms among adopted adolescents. The impact of the age of adoption was treated as a measure of the duration of exposure to deprivation. It was tested after controlling for the influence of adoptee (age, gender, length of time in adoptive family, parents' educational level as a proxy of SES, and marital status) and country factors (social and economic development and health services in the country of origin, and individualistic values and health services in the country of adoption).

Our results support the main hypothesis that attachment deprivation predicts the level of ADHD symptoms, taking into consideration several adoptee and country variables, as well as the interdependence between adolescents according to both their country of origin and their country of adoption. We found that higher ages of adoption predicted higher levels of ADHD symptoms in adolescents. This suggests that neglect in 1 month of life, i.e. the lack of stable care and nurturance which has an impact on the development of attachment relationships, contributes to an increase in the level of ADHD symptoms several years later. As suggested in earlier studies, attachment processes apparently contribute to the development of attention skills and of emotional and behavioral self-control. Children with early attachment deprivation are therefore at risk of exhibiting behavioral problems later on, in particular ADHD symptoms $[5,11,71]$. It should be noted that the adoptees in the current study may have experienced deprivation in a broader sense, not only having missed out on stable attachment relationships but also having lacked essential ingredients needed for healthy physical, 
emotional and cognitive development (e.g. lack of stimulation, toys, and learning materials).

Furthermore, our results support the hypothesis that ADHD symptoms are a characteristic outcome of early deprivation $[31,60]$, whereas the duration of exposure to deprivation was not significantly related to either externalizing or internalizing behavior. Our results corroborate the assumption that early deprivation as experienced by adoptees in their 1 month of life, i.e. lack of assistance with affect regulation in early childhood, lack of reciprocity, lack of empathetic emotional mirroring by the caregiver and associated emotional containment, is associated with poor self-regulation and attention problems, and that this association is more robust than the findings for other behavioral or emotional outcomes. This relation may be explained by the importance of sensitive and responsive interactions in the caregiver-child dyad for the development of a secure relationship in which the child learns to regulate his/her own affect and behavior [22, 39].

Beside these hypotheses, other significant effects of control variables have been found. For individual factors, as expected, ADHD symptoms were at a higher level in boys than in girls. This main effect confirms the results from worldwide prevalence studies [46]. In addition, a lower level of ADHD symptoms was predicted by the length of time in the adoptive family. In other words, additional years spent in their adoptive family setting can be regarded as helping adoptees to recover. Finally, as suggested in the previous developmental studies [33], a reduction in ADHD symptomatology with age was found in our sample, but only in the classical hierarchical regression analysis and not when the variance at the adoptee and country levels was taken into account.

The absence of any effect of marital status or socioeconomic status contradicts previous findings $[17,44,52$, 70]. However, it could be that a measure of the level of marital conflict would be more predictive of the level of ADHD symptoms in adolescents than a dichotomous classification of adoptive parents as either living together (first group) or living separately or a single adoptive mother (second group). Also, it could be that the range in educational level of the adoptive parents was not large enough to display significant relations with the level of ADHD symptoms. This range is somewhat limited because of the policy of selection of the adoptive families according to their socio-demographic characteristics.

The results displayed for the cultural factors were in line with those from previous research [3, 10, 34]. A significant effect was shown for the WHO ranking of both the country of origin and the country of adoption. This stresses the importance of the quality of the health services for children institutionalized prior to their adoption in their country of origin but also for these children after their adoption. This point relates in particular to the system's responsiveness, which is the main factor that determines the country ranking; this makes sense in light of the theoretical background to attachment deprivation.

Although important from both clinical and research perspectives, this study is by no means definitive. A first important limitation in studies relying on adoption is the bias in the association between the origin of the children and the country of adoption. This is because individual countries have agreements on the adoption of children with certain countries rather than others. For example, all of the 37 Russian children had been adopted in Canada. Such a bias has implications with regard to both the number and the size of the level-2 cells in the analyses. A second limitation in studies on adoption in general as well as in the current study is the lack of qualitative information about the individual care and nurturance that children have actually received before adoption. The age of adoption is in most cases the only variable that can be used as a measure of the duration of exposure to early deprivation in care and nurturance. Although the age of adoption may serve as a rough, but effective proxy for considering effects of deprivation (see also [67]), the study may also reveal a whole range of health and other forms of deprivation as causal, and these may be part of the early lives of children before their adoption. Another alternative hypothesis adjusting to a different culture and family becomes more and more difficult as children grow older. A third limitation is that the current findings were based on parent information only and did not include teacher- or self-reports.

It should be noted that meta-analytical evidence has convincingly shown that adoption is a positive and effective intervention in adopted children's lives. Despite the experiences of deprivation, adoptees show catch-up growth in the domains of physical, social-emotional, and cognitive development, outperforming those children unfortunately left behind in institutional care [27]. Adoptees also display more behavior problems (including ADHD) than their nonadopted counterparts, but this concerns a minority of adoptees. The large majority function well, and much better than might be expected based on their background of deprivation [28].

In conclusion, in a large cross-national study including 641 adopted adolescents in five countries we tested the contribution of early deprivation to later ADHD symptoms and found that the age of adoption significantly predicted the level of ADHD symptoms, with increasing ages of adoption predicting higher levels of ADHD. This outcome suggests that deprivation of stable and sensitive care in infancy may have long-lasting consequences for children's development. Implications for policy and practice are that adoptive parents should be supported to help their children recover from experiences of deprivation and that children 
without parental care should be placed in foster or adoptive families as early as possible to avoid or prevent experiences of institutional deprivation.

Conflict of interest On behalf of all authors, the corresponding author states that there is no conflict of interest.

\section{References}

1. Abrines N, Barcons N, Marre D, Brun C, Fornieles-Deu A, Fumadó V (2012) ADHD-like symptoms and attachment in internationally adopted children. Attach Hum Dev 14(4):405-423

2. Achenbach TM, Rescorla LA (2001) Manual for the ASEBA school-age forms and profiles. University of Vermont, research center for children, youth and families, Burlington

3. Barcons-Castel N, Fornieles-Deu A, Costas-Moragas C (2011) International adoption: assessment of adaptive and maladaptive behavior of adopted minors in Spain. Span J Psychol 14(1):123-132

4. Barkley RA (1997) Behavioral inhibition, sustained attention, and executive functions: constructing a unifying theory of ADHD. Psychol Bull 121(1):65-94

5. Barkley RA (2010) Deficient emotional self-regulation: a core component of attention-deficit/hyperactivity disorder. J ADHD Relat Disord 1:5-37

6. Bauermeister JJ, Canino G, Polanczyk G, Rohde LA (2010) ADHD across cultures: is there evidence for a bidimensional organization of symptoms? J Clin Child Adolesc Psychol 39(3):362-372

7. Beijersbergen MD, Juffer F, Bakermans-Kranenburg MJ, van Ijzendoorn MH (2012) Remaining or becoming secure: parental sensitive support predicts attachment continuity from infancy to adolescence in a longitudinal adoption study. Dev Psychol 48(5):1277-1282

8. Bellgrove MA, Barry E, Johnson KA, Cox M, Dáibhis A, Daly M, Kirley A (2008) Spatial attentional bias as a marker of genetic risk, symptom severity, and stimulant response in ADHD. Neuropsychopharmacology 33(10):2536-2545

9. Brewis A, Schmidt KL, Meyer M (2000) ADHD-type behavior and harmful dysfunction in childhood: a cross-cultural model. Am Anthropol 102(4):823-828

10. Bussing R, Gary FA, Mills TL, Garvan CW (2003) Parental explanatory models of ADHD: gender and cultural variations. Soc Psychiatry Psychiatr Epidemiol 38(10):563-575

11. Cardona JF, Facundo M, Escobar J, Lopez J, Ibanez A (2012) Potentials consequences of abandonment in preschool-age: neuropsychological findings in institutionalized children. Behav Neurol 25:1-11

12. CIA (2009) The World Factbook. Washington, DC: retieved from https://www.cia.gov/library/publications/the-world-factbook/ index.html Retrieved from https://www.cia.gov/library/publications/ the-world-factbook/index.html

13. Clarke L, Ungerer J, Chahoud K, Johnson S, Stiefel I (2002) Attention deficit hyperactivity disorder is associated with attachment insecurity. Clin Child Psychol Psychiatry 7(2):179-198

14. Crittenden PM, Kulbotten GR (2007) Familial contributions to ADHD: an attachment perspective. Tidsskrift Norsk Psykol 44(10): 1220-1229

15. Dallos R, Smart C (2011) An exploration of family dynamics and attachment strategies in a family with $\mathrm{ADHD} /$ conduct problems. Clin Child Psychol Psychiatry 16(4):535-550
16. Dmitrieva J, Chen C, Greenberger E, Gil-Rivas V (2004) Family relationships and adolescent psychosocial outcomes: converging findings from Eastern and Western cultures. J Res Adolesc 14(4):425-447

17. Elmund A, Lindblad F, Vinnerljung B, Hjern A (2007) Intercountry adoptees in out-of-home care: a national cohort study. Acta Paediatr 96(3):437-442

18. Finzi-Dottan R, Manor I, Tyano S (2006) ADHD, temperament, and parental style as predictors of the child's attachment patterns. Child Psychiatry Hum Dev 37(2):103-114

19. Galéra C, Melchior M, Chastang JF, Bouvard MP, Fombonne E (2009) Childhood and adolescent hyperactivity-inattention symptoms and academic achievement 8 years later: the GAZEL Youth study. Psychol Med A J Res Psychiatry Allied Sci 39(11):1895-1906

20. Gunnar MR, van Dulmen MHM (2007) Behavior problems in postinstitutionalized internationally adopted children. Dev Psychopathol 19(1):129-148

21. Habersaat SA, Tessier R, Pierrehumbert B (2011) International adoption: influence of attachment and maternal monitoring style in the emergence of behavioural problems in adolescence in relation to age at adoption. Schweizer Archiv für Neurologie und Psychiatrie 162(1):21-26

22. Haddad PM, Garralda ME (1992) Hyperkinetic syndrome and disruptive early experiences. Br J Psychiatry 161:700-703

23. Hechtman L (1996) Families of children with attention deficit hyperactivity disorder: a review. Can J Psychiatry 41(6):350-360

24. Hildyard KL, Wolfe DA (2002) Child neglect: developmental issues and outcomes. Child Abuse Negl 26(6-7):679-695

25. Hofstede G (2012) National cultural dimensions, from retrieved http://geert-hofstede.com/national-culture.html

26. Hofstede G, Hofstede GJ, Minkov M (eds) (2010) Cultures and organizations: software of the mind, 3rd edn. Mc Graw Hill, USA

27. Jaffari-Bimmel N, Juffer F, van Ijzendoorn MH, BakermansKranenburg MJ, Mooijaart A (2006) Social development from infancy to adolescence: longitudinal and concurrent factors in an adoption sample. Dev Psychol 42(6):1143-1153

28. Juffer F, van IJzendoorn MH (2005) Behavior problems and mental health referrals of international adoptees: a meta-analysis. J Am Med Assoc 293(20):2501-2515

29. Keown LJ (2012) Predictors of boys' ADHD symptoms from early to middle childhood: the role of father-child and motherchild interactions. J Abnorm Child Psychol 40(4):569-581

30. Keskin G, Cam O (2010) Adolescents' strengths and difficulties: approach to attachment styles. J Psychiatr Ment Health Nurs 17(5):433-441

31. Kreppner JM, O'Connor TG, Rutter M, Beckett C, Castle J, Croft C, Groothues C (2001) Can inattention/overactivity be an institutional deprivation syndrome? J Abnorm Child Psychol 29(6):513-528

32. Lacalle M, Ezpeleta L, Doménech JM (2012) DSM-oriented scales of the Child Behavior Checklist and Youth Self-Report in clinically referred Spanish children. Span J Psychol 15(1):377-387

33. Langberg JM, Epstein JN, Altaye M, Molina BSG, Arnold LE, Vitiello B (2008) The transition to middle school is associated with changes in the developmental trajectory of ADHD symptomatology in young adolescents with ADHD. J Clin Child Adolesc Psychol 37(3):651-663

34. Lee K, Neuharth-Pritchett S (2008) Attention deficit/hyperactivity disorder across cultures: development and disability in contexts. Early Child Dev Care 178(4):339-346

35. Lindblad F, Weitoft GR, Hjern A (2010) ADHD in international adoptees: a national cohort study. Eur Child Adolesc Psychiatry 19(1):37-44 
36. Maas CJM, How JJ (2005) Sufficient sample sizes for multilevel modeling. Methodology 1(3):86-92

37. Merz EC, McCall RB (2010) Behavior problems in children adopted from psychosocially depriving institutions. J Abnorm Child Psychol 38(4):459-470

38. Mikami AY, Hinshaw SP (2006) Resilient adolescent adjustment among girls: buffers of childhood peer rejection and attentiondeficit/hyperactivity disorder. J Abnorm Child Psychol 34(6):825-839

39. Mikulincer M, Shaver PR, Pereg D (2003) Attachment theory and affect regulation: the dynamics, development, and cognitive consequences of attachment-related strategies. Motiv Emot 27(2):77-102

40. Muris P, Maas A (2004) Strengths and difficulties as correlates of attachment style in institutionalized and non-institutionalized children with below-average intellectual abilities. Child Psychiatry Hum Dev 34(4):317-328

41. Nakamura BJ, Ebesutani C, Bernstein A, Chorpita BF (2009) A psychometric analysis of the child behavior checklist DSM-oriented scales. J Psychopathol Behav Ass 31(3):178-189

42. Niederhofer H (2009) Attachment as a component of attentiondeficit hyperactivity disorder. Psychol Rep 104(2):645-648

43. Peterson RA (ed) (2000) Constructing effective questionnaire. Oxford University Press, London

44. Pheula GF, Rohde LA, Schmitz M (2011) Are family variables associated with ADHD, inattentive type? A case-control study in schools. Eur Child Adolesc Psychiatry 20(3):137-145

45. Pinto C, Turton P, Hughes P, White S, Gillberg C (2006) ADHD and infant disorganized attachment: a prospective study of children next-born after stillbirth. J Atten Disord 10(1):83-91

46. Polanczyk G, de Lima MS, Horta BL, Biederman J, Rohde LA (2007) The worldwide prevalence of ADHD: a systematic review and metaregression analysis. Am J Psychiatry 164(6):942-948

47. Raudenbush SW, Bryk AS, Cheong YF, Congdon R (eds) (2001) HLM5 hierarchical linear and non-linear modeling. Sci Softw Intern, Lincolnwood

48. Roessner V, Becker A, Rothenberger A, Rohde LA, Banaschewski T (2007) A cross-cultural comparison between samples of Brazilian and German children with ADHD/HD using the Child Behavior Checklist. Eur Arch Psychiatry Clin Neurosci 257(6):352-359

49. Rutter M, Beckett C, Castle J, Colvert E, Kreppner J, Mehta M, Sonuga-Barke E (2007) Effects of profound early institutional deprivation: an overview of findings from a UK longitudinal study of Romanian adoptees. Europ J Dev Psychol 4(3):332-350

50. Rutter M, Colvert E, Kreppner J, Beckett C, Castle J, Groothues C, Sonuga-Barke EJS (2007) Early adolescent outcomes for institutionally-deprived and non-deprived adoptees. I: disinhibited attachment. J Child Psychol Psychiatry 48(1):17-30

51. Rydell A-M (2010) Family factors and children's disruptive behaviour: an investigation of links between demographic characteristics, negative life events and symptoms of ODD and ADHD. Soc Psychiatry Psychiatr Epidemiol 45(2):233-244

52. Rydell A-M (2010) Family factors and children's disruptive behaviour: an investigation of links between demographic characteristics, negative life events and symptoms of ODD and ADHD. Soc Psychiatry Psychiatr Epidemiol 45(2):233-244

53. Sharma AR, McGue MK, Benson PL (1996) The emotional and behavioral adjustment of United States adopted adolescents: part II. Age at adoption. Child Youth Serv Rev 18(1-2):101-114

54. Simmel C, Brooks D, Barth RP, Hinshaw SP (2001) Externalizing symptomatology among adoptive youth: prevalence and preadoption risk factors. J Abnorm Child Psychol 29(1):57-69

55. Smith SL, Howard JA, Monroe AD (2000) Issues underlying behavior problems in at-risk adopted children. Child Youth Serv Rev 22(7):539-562
56. Snijders TAB (2005) Power and sample size in multilevel modeling. Encycl Statist Behav Sci 3:1570-1573

57. Snijders TAB, Bosker R (eds) (1999) Multilevel analysis. Sage, London

58. Sonuga-Barke E (2003) The dual pathway model of AD/HD: an elaboration of neuro-developmental characteristics. Neurosci Biobehav Rev 27(7):593-604

59. Sonuga-Barke E (2005) Causal models of attention-deficit/ hyperactivity disorder: from common simple deficits to multiple developmental pathways. Biol Psychiatry 57(11):1231-1238

60. Sonuga-Barke E, Rubia K (2008) Inattentive/overactive children with histories of profound institutional deprivation compared with standard ADHD cases: a brief report. Child Care Health Dev 34(5):596-602

61. Sonuga-Barke E, Bitsakou P, Thompson M (2010) Beyond the dual pathway model: evidence for the dissociation of timing, inhibitory, and delay-related impairments in attention-deficit/ hyperactivity disorder. J Am Acad Child Adolesc Psychiatry 49(4):345-355

62. Stiefel I (1997) Can disturbance in attachment contribute to attention deficit hyperactivity disorder? Clin Child Psychol Psychiatry 2:45-64

63. Super CM, Axia G, Harkness S, Welles-Nyström B, Zylicz PO, Parmar P, McGurk H (2008) Culture, temperament, and the "difficult child": a study of seven Western cultures. Europ J Dev Sci 2(1-2):136-157

64. Tessier R, Moss E, Nadeau L, Larose S, Tarabulsy G (2005) L'adoption internationale au Québec de 1985 à 2002. L'adaptation sociale des enfants nés à l'étranger et adoptés par des familles du Québec. Rapport de recherche présenré au Secrétariat à l'Adoption Internationale (SAI). Ministère de la Santé et des Services Sociaux, Québec

65. Tieman W, van der Ende J, Verhulst FC (2006) Social functioning of young adult intercountry adoptees compared to nonadoptees. Soc Psychiatry Psychiatr Epidemiol 41(1):68-74

66. Ulleb $\varnothing$ AK, Posserud M-B, Heiervang E, Obel C, Gillberg C (2012) Prevalence of the ADHD phenotype in 7- to 9-year-old children: effects of informant, gender and non-participation. Soc Psychiatry Psychiatr Epidemiol 47(5):763-769

67. van den Dries L, Juffer F, Van IJzendoorn MH, BakermansKranenburg MJ (2009) Fostering security? A meta-analysis of attachment in adopted children. Child Youth Serv Rev 31(3):410-421

68. van der Vegt EJM, Tieman W, van der Ende J, Ferdinand RF, Verhulst FC, Tiemeier H (2009) Impact of early childhood adversities on adult psychiatric disorders. Soc Psychiatry Psychiatr Epidemiol 44(9):724-731

69. Vondra JI, Shaw DS, Swearingen L, Cohen M, Owens EB (2001) Attachment stability and emotional and behavioral regulation from infancy to preschool age. Dev Psychopathol 13(1):13-33

70. Wadsworth ME, Achenbach TM (2005) Explaining the link between low socioeconomic status and psychopathology: testing two mechanisms of the social causation hypothesis. J Consult Clin Psychol 73(6):1146-1153

71. Walcott CM, Landau S (2004) The relation between disinhibition and emotion regulation in boys with attention deficit hyperactivity disorder. J Clin Child Adolesc Psychol 33(4):772-782

72. Waters SF, Virmani EA, Thompson RA, Meyer S, Raikes HA, Jochem R (2010) Emotion regulation and attachment: unpacking two constructs and their association. J Psychopathol Behav Assess 32(1):37-47

73. Weinberg RA, Waldman I, van Dulmen MHM, Scarr S (2004) The minnesota transracial adoption study: parent reports of psychosocial adjustment at late adolescence. Adopt Quart 8(2):27-44 
74. Wiik KL, Loman MM, Van Ryzin MJ, Armstrong JM, Essex MJ, Pollak SD, Gunnar MR (2011) Behavioral and emotional symptoms of post-institutionalized children in middle childhood. J Child Psychol Psychiatry 52(1):56-63
75. Xing Tan T, Marfo K (2006) Parental ratings of behavioral adjustment in two samples of adopted Chinese girls: age-related versus socio-emotional correlates and predictors. Appl Dev Psychol 27:14-30 